\title{
LA AGRICULTURA DE PRECISIÓN COMO FUENTE DE ALIMENTO GLOBAL PARA 2050
}

MARCELLA GONZALES

- Profesora de Agribusiness Management

Dirección de Administración y Agronegocios

Facultad de Negocios, UPC

\begin{abstract}
RESUMEN
La tecnología está generando cambios en la agricultura alrededor del mundo. El uso de big data está mejorando la productividad de los cultivos y reduciendo la contaminación ambiental. En la evolución de los cambios tecnológicos, los agricultores fueron desarrollando nuevas herramientas para lograr un rendimiento superior pero con un enfoque en el área cultivada. Sin embargo, la agricultura de precisión, a través de tecnologías como el Global Positioning System (GPS), está logrando un análisis personalizado por cultivo, alcanzando de esta manera mayores niveles de producción. Al afectar a la productividad laboral positivamente e incrementar la producción agrícola considerablemente, toda esta evolución podría hacer de las deficiencias en el agro y de la escasez de los alimentos algo del pasado.
\end{abstract}

Palabras clave: Agricultura de precisión, productividad, tecnología.

\section{ABSTRACT}

The objective of this essay is to provide some thoughts on how technology is changing world agriculture. Big data is improving productivity of crops and reducing pollution. In this technological evolution, while farmers develop new tools to achieve superior output performance, with a scope in cultivated area, precision agriculture is making a personalized analysis per crop, by using, for example, global positioning system (GPS). By affecting farm labor productivity positively and increasing agricultural output considerably, this could make of food shortages something of the past.

Keywords: Precision farming, productivity, technology.

El Global Positioning System (GPS), la automatización y la big data están cambiando la agricultura en todo el mundo.

Imagine un mundo en el que cada planta o animal que requiere de una determinada alimentación individual recibe la atención personalizada de agricultores robóticos que suministran la cantidad exacta y justa de nutrientes necesarios en cada etapa de su crecimiento.
Con la necesidad de alimentar a una población mundial que, según proyecciones de las Naciones Unidas (2015), llegará a 9,6 miles de millones de personas en 2050, hay cierta urgencia en perfeccionar este tipo de métodos. Afortunadamente, con el desarrollo de la tecnología basada en la agricultura de precisión, ese mundo no está lejos de ser una realidad.

Utilizando big data y nuevas tecnologías, existe el potencial de transformar la agricultura tal como la conocemos hoy, aumentando la producción de alimentos, fibra y combustible, al mismo tiempo que se reducen la contaminación y otras huellas ambientales de la agricultura, producto del progreso económico. Es más, la agricultura de precisión transformará la ventaja comparativa ricardiana de muchas regiones geográficas y forzará una reorganización de la producción agrícola.

Las tecnologías de agricultura de precisión ya se encuentran bien implantadas en Estados Unidos, en Europa y en varios países industrializados. La tendencia comenzó con el uso del GPS desde inicios de la década de 1980 para monitorear los rendimientos de los cultivos y orientar la aplicación de fertilizantes. A medida que la tecnología digital se extienda a las granjas del mundo, la robótica, los grandes datos y otros usos de la información electrónica serán tan comunes como los tractores y las cosechadoras, lo cual modificará en gran medida la forma en que las personas manejan granjas, viñedos, huertos, bosques y ganado. Esta transformación está casi asegurada, dadas las invenciones tecnológicas de los últimos años.

Pero lo que es aún incierto es cómo estos cambios pueden afectar la actividad agrícola y el mercado laboral en el sentido local y regional. La cultura actual de la alimentación - the farm-to-table movement-, el aumento de la agricultura orgánica, las preocupaciones sobre los cultivos genéticamente modificados y el uso del agua en algunas áreas generan un debate interesante sobre el planteamiento de políticas de implementación.

Tiempo atrás, los agricultores cultivaban principalmente para alimentarse a sí mismos y a sus familias. Se descubrió qué plantas eran las más adecuadas para los suelos en pequeñas parcelas, aunque los rendimientos eran bajos. Pero, a medida que la historia progresaba y a los agricultores se les facilitaba el uso del conocimiento científico, todo esto ayudado de la experiencia mecánica que iban adquiriendo, se desarrolló maquinaria para 
reducir el trabajo manual, y productos químicos para proteger y nutrir los cultivos. Se llevaron grandes métodos de producción a la agricultura, y, para algunos cultivos, los rendimientos se multiplicaron por diez desde el siglo xIx hasta nuestros días.

Sin embargo, hoy la agricultura de precisión está invirtiendo estos enfoques estandarizados, y está permitiendo a los agricultores personalizar cada hectárea cultivada para el máximo rendimiento posible de cada planta.

Fue el 1983 que la agricultura de precisión se comenzó a emplear, cuando el Gobierno de Estados Unidos puso la tecnología GPS a disposición del sector civil. Esta tecnología encontró una audiencia lista entre los agricultores estadounidenses, quienes rápidamente adoptaron el uso del GPS, principalmente porque les ayudó, por ejemplo, a reducir los lugares que inadvertidamente perdían por aplicar dos veces fertilizantes o pesticidas, lo cual proporcionó ahorros significativos. De acuerdo con una encuesta realizada por Purdue CropLife, para el año 2015 casi el 90\% de los distribuidores de fertilizantes había usado el GPS para aplicar fertilizantes a la medida en Estados Unidos.

Otra aplicación del GPS, que se ha hecho ya una práctica común, es para administrar fertilizantes a diferentes ritmos en un campo. ¿Cómo? Los agricultores prueban sus campos en puntos específicos para determinar los niveles de acidez, fósforo y potasio, y luego un agrónomo mapea fertilizantes recomendados para cada área, de modo que se maximiza la producción. Un separador de fertilizantes guiado por GPS sigue el mapa para aplicar los nutrientes en los lugares correctos. Aún hoy, en algunas partes de Estados Unidos y Europa este tipo de aplicaciones sigue siendo costoso, principalmente por las pruebas iniciales de suelo y por tener que hacer el mapa de recomendación.

De modo paralelo, nos encontramos con el desarrollo de sensores que analizan el color de una planta para determinar sus necesidades de fertilizantes (una planta con muy poco nitrógeno tiende a tornarse verde pálido o amarillo). Estos sensores pueden colocarse en la parte delantera de un tractor para que, en pleno movimiento, sean escaneadas las plantas, permitiéndose, de ser necesario, la aplicación automática de la dosis requerida de fertilizante por la parte posterior del vehículo.

Los drones, por su lado, son otra nueva área de tecnología que ha ido ganando una mayor participación en el sector agrícola, brindando una exploración del cultivo en sí, manejo adecuado del ganado y la recolección de datos en agricultura a gran escala. La encuesta realizada por Purdue CropLife antes referida informó que el 16\% de los retailers en Estados Unidos ofrecían servicios de imágenes de drones, y que esos minoristas proporcionaban imágenes solo en el $2 \%$ del área de cultivo de sus clientes, lo que generó el cuestionamiento sobre el costo versus la rentabilidad de los drones en una operación agrícola.

Mientras que los drones son la solución tecnológica de alto perfil, puede resultar más barato y más fácil para los agricultores el descargar imágenes de microsatélites de internet, para así explorar los cultivos y recopilar data.
Aunque la industria de la agricultura ha experimentado con la tecnología del satélite desde la década de 1970, los problemas - tales como el alto costo y la brecha de tiempo entre la captura y la entrega de la imagen- han sido constantes. Debido a estos retos, solo el $18 \%$ de la superficie cultivada en Estados Unidos es manejada con imágenes satelitales o aéreas. Los microsatélites pueden acelerar esa tendencia.

Finalmente, la tecnología que probablemente transformará más a la agricultura es la robótica. Aunque todavía en sus primeras etapas en toda la industria, al menos 8000 granjas lecheras del planeta entero utilizan utilizan sistemas de ordeño robótico. La vaca es entrenada para que, cuando siente la necesidad de ser ordeñada, entre a un establo en el que unos brazos robóticos lavarán su ubre, unirán las ventosas de ordeño y las separarán cuando se ordeñe.

El uso del GPS también ha motivado la aparición de equipos agrícolas autónomos. Así como los automóviles sin conductor empiezan a verse, los fabricantes están probando tractores que no requieren de choferes. La eliminación de los conductores humanos conlleva otros cambios también, ya que modifica los criterios de diseño de los equipos agrícolas, lo que les permite ser mucho más pequeños.

Las alternativas para la mecanización convencional pueden ser especialmente importantes para las operaciones agrícolas de países en desarrollo, donde la mano de obra agrícola es cada vez más escasa y costosa, y no por ser necesariamente más productiva, sino debido a la migración rural-urbana de los jóvenes.

En el futuro, la supervisión, la reparación y el mantenimiento de los robots probablemente se conviertan en habilidades clave para los agricultores.

Así que, imagínese: si un agricultor en un país en desarrollo pudiese comprar un robot básico capaz de plantar, deshierbar y cosechar, y eso por el costo de una moto, la rentabilidad no sería solo por mano de obra, sino también para la mecanización convencional. La rápida y generalizada adopción de la tecnología de telefonía móvil en el mundo en desarrollo sugiere que, si las empresas de agricultura de precisión y los investigadores pueden desarrollar tecnologías que resuelvan los problemas de los pequeños agricultores a bajo costo, hay un enorme mercado en espera.

El uso de la agricultura de precisión tiene, pues, beneficios tanto en el mediano como en el largo plazo. En el mediano plazo, para cultivos como el espárrago y la uva significa que se requeriría incluso menos trabajadores para la producción. La orientación hacia el GPS permite a los agricultores lograr más y, al reducir la fatiga, trabajar mejor, especialmente en las épocas de campaña. A largo plazo, por su parte, la agricultura de precisión está creando una demanda de trabajadores más calificados. Ya los proveedores y las empresas de equipamiento agrícola en todo el mundo están compitiendo por los empleados que entienden de GPS, sensores, drones y análisis de datos espaciales. En el futuro, la supervisión, la reparación y el mantenimiento de los robots probablemente se conviertan en habilidades clave para los agricultores. Con 
la robótica, la necesidad de mano de obra no calificada para deshierbar y cosechar los cultivos debería casi desaparecer

La agricultura de precisión tiene el potencial de ayudar a que la producción agrícola sea más eficiente y mejor para el medioambiente en un momento en el que habrá más bocas para alimentar en la Tierra.

Datos:

- El 47\% de los empleos estadounidenses están en riesgo de ser asumidos por la automatización en los próximos 20 años (Benedikt \& Osborne, 2013).

- Podrían ser 2,1 millones de nuevos empleos los producidos en la próxima ola de automatización del trabajo (Mercader, 2017).

\section{REFERENCIAS}

Benedikt, C. \& Osborne, M. (2013). The future of employment: How susceptible are jobs to computerisation? Recuperado de https://www. oxfordmartin.ox.ac.uk/downloads/academic/The_ Future_of_Employment.pdf

Mercader, J. (2017). La robotización y el futuro del trabajo. Recuperado de http://replicantelegal.com/larobotizacion-y-el-futuro-del-trabajo/

Organización de las Naciones Unidas. (2015). Población. Recuperado de http://www.un.org/es/sections/issuesdepth/population/index.html 